Original article

\title{
Influence of anxiety on wrist tapping parameters and individual perception of one minute in healthy adults and in patients with juvenile myoclonic epilepsy
}

\author{
Ekaterina A. Narodova ${ }^{1}$, Natalia A. Shnayder ${ }^{2}$, Valeria V. Narodova ${ }^{1}$, Evgeny E. Erahtin ${ }^{3}$, Olga S. Shilkina ${ }^{1}$, \\ Polina V. Moskaleva ${ }^{1}$

\footnotetext{
${ }^{1}$ Krasnoyarsk State Medical University n.a. Prof. V.F. Voino-Yasenetsky, Krasnoyarsk, Russia

${ }^{2}$ St.Petersburg V.M. Bekhterev Psychoneurological Research Institute, Saint Petersburg, Russia

${ }^{3}$ Krasnoyarsk Interdistrict Clinical Emergency Hospital n.a. N.S. Karpovich, Krasnoyarsk, Russia
}

Received 14 August 2018, Revised 14 September 2018, Accepted 13 October 2018

(C) 2018, Narodova E.A., Shnayder N.A., Narodova V.V., Erahtin E.E., Shilkina O.S., Moskaleva P.V.

(C) 2018, Russian Open Medical Journal

Abstract: Aim - To study the influence of anxiety on parameters of wrist tapping in normal conditions and in juvenile myoclonic epilepsy (JME) Material and Methods - We evaluated 105 people aged 16 to 55 years old (average: 31.6 \pm 10.2 years). The sample was comprised of two groups: first (I) group - healthy volunteers $(n=60)$; second (II) group - patients with JME $(n=45)$. Every group was stratified into two subgroups: subgroup la $(n=33)$ - healthy volunteers without symptoms of anxiety; subgroup Ib $(n=27)$ - healthy volunteers with subclinical anxiety; subgroup IIa $(n=19)$ - patients with JME without symptoms of anxiety; subgroup IIb $(n=26)$ - patients with JME with subclinical anxiety. Wrist tapping parameters were studied using method of our authorship named «Method of influencing a person's individual rhythm through exogenous rhythmic stimulation». We studied reference ranges of basic characteristics of wrist tapping.

Results - Comparison of basic parameters of wrist tapping in subgroups la and lla revealed a trend towards an increase in rhythm stability in patients with JME when compared to healthy volunteers. At the same time, subclinical anxiety led to a pronounced increase in frequency of individual rhythm in subgroup Ilb when compared to subgroup la.

Conclusion - Influence of anxiety on wrist tapping parameters is more pronounced in patients with JME when compared to healthy volunteers.

Keywords: juvenile myoclonic epilepsy, wrist tapping, parameters, anxiety, individual rhythm, individual perception of minute.

Cite as Narodova EA, Shnayder NA, Narodova VV, Erahtin EE, Shilkina OS, Moskaleva PV. Influence of anxiety on wrist tapping parameters and individual perception of one minute in healthy adults and in patients with juvenile myoclonic epilepsy. Russian Open Medical Journal $2018 ; 7$ : e0415.

Correspondence to Ekaterina A. Narodova. E-mail: katya_n2001@mail.ru.

\section{Introduction}

Juvenile myoclonic epilepsy (JME) is one of the most common forms of idiopathic generalized epilepsy. Clinical presentation of this disorder includes myoclonias (usually in upper extremities) with tonic-clonic generalized seizures and absences [1]. JME belongs to age-dependent type of idiopathic generalized epilepsy. Age of onset is usually within 8 to 26 years, and incidence peaks at 14-16 years. The onset is triggered by stress, disturbances in circadian rhythm (night sleep deprivation, early wake-ups), menarche in teenage girls [2]. Despite preserved intelligence, there is a high risk of anxiety and depressive disorders. This leads to social disadaptation and unemployment, which considerably aggravates social prognosis for patients with JME [3].

Dysfunction of frontal lobe, which is responsible for decisionmaking, individuality, motion and speech, was demonstrated in patients with JME [4]. Tapping is known as a psychomotor test for evaluation of brain psychophysiological functions, such as time perception [5]. Tapping without any external influence with subject-defined rhythm is a "biological constant" which reflects rates of nervous processes and endogenous processes within central nervous system (CNS) [6]. According to V.A. Rudnev, socalled "intrinsic time" is a genetic core of all motor activity bearing features of a whole population, as well as individual features of a specific human being [7]. Intrinsic time manifests itself as set internal rhythms. Spontaneous rhythm generated by tapping without any programmed external stimulus is registered as a socalled individual rhythm, which is exactly a genetically coded intrinsic time.

There is a large number of studies dedicated to individual rhythm in humans, its "maturation» in late ontogenesis and its disruption in certain neurological conditions (cerebral palsy, stroke, head injury, parkinsonism) [8-11].

Individual rhythm reflects balance in CNS function and its disruption typically suggests disintegration of brain activity [6]. As patients with epilepsy have pathological activation of brain neurons, which is stressful for CNS, we thought that formation of an epileptic system may change an individual rhythm in a given patient. 
V.A. Rudnev (1982) thought that movement cyclicity in wrist tapping is a natural statistical pattern, a standard against which certain parameters may be measured. Consequently, study of these biologically appropriate movements gives us the ability to determine tendencies towards certain paces and rhythms of motion, which may appear in various disorders at different levels of human nervous system [7].

Emergence of a pathological dominant, which is an extremely amplified locus of excitation in CNS [12], may be seen during formation of an epileptic system, as in JME. We hypothesized that this event will affect wrist tapping parameters accordingly, and that this may be used in diagnostics and rehabilitation in adults with epilepsy. An example of how individual time perception may be studied is a screening test designed to evaluate individual perception of one minute in normal and pathological conditions [13-15]. It was found that during exams individual perception of one minute in students decreases to $52.3 \pm 5.6$ seconds. Research has shown that perceived duration of one minute is in reverse proportion to psychoemotional overload in a student [16]. Consequently, it is rational to assume that disintegration of CNS activity in epilepsy may lead to alterations in individual perception of one minute.

Recovery of individual rhythm and individual minute perception when combined with clinical presentation and electroencephalography (EEG) monitoring data may suggest positive dynamics in epilepsy patients' condition. Moreover, study of wrist tapping parameters and individual perception of minute in patients with JME may allow timely detection of anxiety disorders, potentially leading to decompensation of a primary condition, at subclinical stage and, therefore, timely correction of medical therapy regimen.

The goal of this study was to evaluate the influence of anxiety on wrist tapping parameters in normal conditions and in JME.

\section{Material and Methods}

This study was approved by local ethics committee of Krasnoyarsk State Medical University n.a. Prof. V.F.VoinoYasenetsky (Krasnoyarsk, Russia) (protocol №77/2017, June 26, 2017). Study was performed in several facilities: Neurologic Center of Epileptology, Neurogenetics and Brain Studies of University Clinic; Department of Nervous Diseases with Course of Medical Rehabilitation of Institute of Postgraduate Education; Department of Medical Genetics and Clinical Neurophysiology of Institute of Postgraduate Education.

\section{Participants}

Overall, 105 subjects aged 16-55 years (median with interquartiles range: $30(22,39)$ years) took part in this study. General sample was divided into two groups:

i) first (I) group (control group) was comprised of 60 healthy volunteers aged $30(22,44)$ years;

ii) second (II) group (study group) was comprised of 45 patients with JME aged $30(24,35)$ years.

Every group was stratified into two subgroups:

i) subgroup la ( $n=33 ; 32(22,47)$ years) - healthy volunteers without reliable manifestation of anxiety symptoms (0-7 points on the Hospital Anxiety and Depression Scale (HADS)); ii) subgroup Ib ( $\mathrm{n}=27 ; 29(22,42)$ years $)$ - healthy volunteers with subclinically manifested anxiety (8-10 points on HADS);

iii) subgroup Ila ( $n=19 ; 30(22,37)$ years) - patients with JME without reliably identified symptoms of anxiety (07 points on HSAD);

iv) subgroup Ilb ( $n=26 ; 29(26,34)$ years) - patients with JME and subclinically manifested anxiety (8-10 points on HSAD).

Inclusion criteria for group I (control group):

i) healthy adults;

ii) right-handedness;

iii) male sex and female sex;

iv) age period: juvenile (males 17-21 years, females 16-20 years), first period middle-aged (males 22-35 years, females 21-35 years), second period middle-aged (males $36-60$ years, females $36-55$ years);

v) Russian-speaking Caucasians;

vi) signed informed consent form.

Exclusion criteria for group I (control group):

i) children and teenagers;

ii) left-handedness;

iii) refusal to participate in this study;

iv) participation in other studies;

v) acute and chronic neurological, psychiatric and endocrine conditions for duration of the study;

vi) alcohol intake ( 2 drinks and more for the last 2 weeks);

vii) use of recreational drugs during the study and in medical history.

Inclusion criteria for group II (study group):

i) patients with JME;

ii) male sex and female sex;

iii) right-handedness;

iv) age period: juvenile (males 17-21 years, females $16-20$ years), first period middle-aged (males 22-35 years, females 21-35 years), second period middle-aged (males $36-60$ years, females $36-55$ years);

v) Russian-speaking Caucasians;

vi) signed informed consent form.

Exclusion criteria for group II (study group):

i) children and teenagers;

ii) left-handedness;

iii) acute and chronic neurological (besides JME), psychiatric and endocrine conditions for duration of the study;

iv) refusal to participate in this study;

v) participation in other studies;

vi) alcohol intake ( 2 drinks and more for the last 2 weeks);

vii) use of recreational drugs during the study and in medical history.

\section{Study methods}

Before the main part of the study, all subjects (groups I and II) completed the Hospital Anxiety and Depression Scale (HADS) 
questionnaire [17], which is designed for express screening to evaluate anxiety and depression levels. This scale was proposed by A.S. Zigmond and R.P. Snaith in 1983 to identify and quantify severity of depression and anxiety in general medical practice. The scale has high discriminant validity for two disorders: anxiety and depression. According to questionnaire results, every group was stratified into 2 subgroups: subgroup «a» - absence of reliable symptoms of anxiety and depression (0-7 points); subgroup «b»subclinical anxiety (8-0 points).

Wrist tapping was studied using method of our authorship, patented in Russian Federation as "Method of influencing a person's individual rhythm through exogenous rhythmic stimulation» (№ 2015111025, October 20, 2016). This method implies finger tapping on screen of a device (Android-based smartphone) (Figure 1) for 1 minute with frequency comfortable for a subject. Software was able to register temporal parameters of this process (number of taps per minute), pressing intensity and steadiness throughout the whole cycle [18]. Software automatically calculated average, maximal and minimal frequency (in $\mathrm{Hz}$ ); average, maximal and minimal interval between taps (in seconds); pressing intensity and percentage of rhythm steadiness. Data of wrist tapping study results were in the form of a list of intervals between taps. An algorithm divided this common list in three parts. Every part had an average value of interval (centroids of a list). They were divided so that all intervals within every part were closer to their centroids, than to centroids of other parts. First of all, initial values for centroids were determined using kmeans++ algorithm. Next, iterative calculation of clusters is performed using k-mean method.

For every of these 3 resulting lists a mean value of interval and mean value of frequency were calculated, and this data was shown on device screen and subsequently subjected to statistical analysis. Also the program calculated a target individual rhythm, which is the hypothetical number of taps per minute for a subject if all the intervals were equal. Target individual rhythm $(\mathrm{Hz})$ was calculated using formula: $x / 60$, where $x$ is the total number of taps per minute. This variable served as a standard to evaluate rhythm steadiness percentage. This way we were able to consider the exact frequency which was as close as possible to target individual rhythm, and its percentage of occurrence in whole sample. We took the frequency with highest occurrence as an individual rhythm.

To determine the individual perception of one minute we used a stopwatch; each subject was told to count to 60 to oneself and to say "stop» after that. Then the stopwatch result was registered. The study was performed in the morning in absence of external sensory stimuli (loud sounds, bright lights), with only patient and doctor present, during wrist tapping procedure. Air temperature in the room was within range of 22-25 degrees Celcius.

Healthy volunteers and patients with JME received no fee for participation in this study, as well as researchers who conducted it.

\section{Statistical analysis}

Database was analyzed using Statistica software, version 10 (StatSoft, USA). Normality of distribution for all variables was checked with Shapiro-Wilk test. Non-parametric variables were obtained in this study. To evaluate significance of differences between variables we used Mann-Whitney test. Findings were considered to be statistically significant when $p$-value was lower than 0.05 .

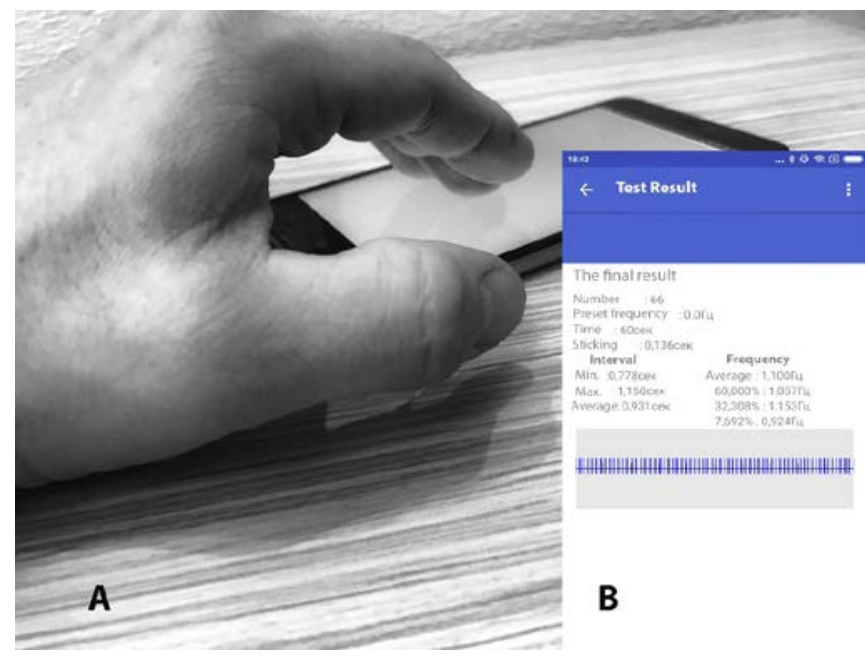

Figure 1. "Method of influencing a person's individual rhythm through exogenous rhythmic stimulation" (Russian Federation patent № 2015111025): A - overall view of a study; B - an example of wrist tapping results in a healthy volunteer [19].

Table 1. Comparison of wrist tapping parameters in healthy volunteers with and without subclinical anxiety

\begin{tabular}{lccr}
\multicolumn{1}{c}{ Parameters } & Group la & Group Ib & p-level \\
\hline Age, years & $32(22,47)$ & $29(22,42)$ & 0.205 \\
Individual minute, seconds & $59(51,66)$ & $53(44,59)$ & 0.060 \\
Individual rhythm, Hz & $1.13(0.99,1.21)$ & $1,53(1.45,1.98)$ & $<0.001$ \\
Rhythm steadiness, \% & $49.0(40.7,52,7)$ & $52.9(48.8,54.7)$ & 0.019 \\
\hline
\end{tabular}

Table 2. Comparison of wrist tapping parameters in patients with JME with and without subclinical anxiety

\begin{tabular}{lccr}
\hline \multicolumn{1}{c}{ Parameters } & Group Ila & Group IIb & p-level \\
\hline Age, years & $30(22,37)$ & $29(26,34)$ & 0.201 \\
Individual minute, seconds & $57(54,64)$ & $59(47,71)$ & 0.100 \\
Individual rhythm, Hz & $1.15(0.98,1.27)$ & $2.48(1,84,3.60)$ & $<0.001$ \\
Rhythm steadiness, \% & $50.8(47.2,54.0)$ & $52.8(45.0,78.0)$ & 0.184 \\
\hline
\end{tabular}

Table 3. Comparison of basic parameters of wrist tapping in healthy volunteers and patients with JME with and without subclinically manifested anxiety

\begin{tabular}{lcc}
\hline \multicolumn{1}{c}{ Parameters } & \multicolumn{2}{c}{$p$-level } \\
& Group la vs Group Ila & Group Ib vs Group IIb \\
\hline Individual minute, seconds & 0.770 & 0.052 \\
Individual rhythm, Hz & 0.610 & 0.020 \\
Rhythm steadiness, \% & 0.040 & 0.580 \\
\hline
\end{tabular}

\section{Results}

Basic characteristics of wrist tapping in group I (control group) are presented in Table 1 . Individual rhythm frequency in healthy individuals without anxiety (subgroup la) was significantly lower than in healthy volunteers of comparable age with subclinically manifested anxiety (subgroup Ib) $-1.13 \mathrm{~Hz}$ versus $1.53 \mathrm{~Hz}$, respectively $(p<0.001)$. The most steady rhythm of wrist tapping was observed in subjects with anxiety (subgroup Ib) when compared to subjects without anxiety - $52.9 \%$ versus $49.0 \%$, respectively $(p=0.019)$. Analysis of obtained results suggests that normative parameters of wrist tapping in young healthy adults and their clinical interpretation should be evaluated with person's 
psychological condition taken into account. It is also necessary to account for even subclinical anxiety, as the latter influences quantitative and qualitative parameters of wrist tapping (primarily, individual rhythm and rhythm steadiness) in normal conditions.

Basic characteristics of wrist tapping in group II (study group) are shown in Table 2 . In comparable study group (patients with JME) there was also an increase in individual rhythm frequency depending on presence or absence of subclinically manifested anxiety $-1.15 \mathrm{~Hz}$ versus $2.48 \mathrm{~Hz}$, respectively $(p=0.009)$. Rhythm steadiness in patients with JME was initially high and wasn't significantly influenced by presence or absence of subclinical anxiety $(p<0.05)$.

Comparative analysis of wrist tapping parameters in groups I and II is presented in Table 3. Comparison of basic parameters of wrist tapping in control group la and study group lla (in subjects without anxiety) revealed a trend toward increase of rhythm steadiness in patients with JME relative to healthy volunteers $(p=0.040)$. However, presence of subclinical anxiety led, first of all, to an increase in frequency of individual rhythm (synchronization phenomenon) in subgroup Ilb when compared to subgroup la $(p=0.040)$

\section{Discussion}

Studying influence of anxiety level on parameters of wrist tapping in healthy adult volunteers and patients with JME using our patented "Method of influencing a person's individual rhythm through exogenous rhythmic stimulation" allowed us to reveal some common trends. Subclinically manifested anxiety leads to an increase in individual rhythm frequency both in healthy volunteers and patients with JME. Nevertheless, acceleration is more pronounced in patients with JME when compared to healthy subjects. It may be possibly related to a presence of primary disease and risk of its decompensation due to anxiety. Anxiety may be a possible trigger for epileptic seizures in patients with JME [3], [6].

We haven't found a statistically significant difference in individual rhythm parameters in subjects without anxiety. Consequently, presence of JME without signs of anxiety doesn't influence individual rhythm significantly. This is possibly explained by an absence of severe defect of brain structure in this condition, but in presence of anxiety it still may influence individual rhythm of a person, doubly increasing its frequency. Anxiety also affects individual minute parameters (shortening it) and rhythm steadiness (making rhythm more steady) both in healthy volunteers and patients with JME.

Thus, parameters of wrist tapping in young healthy adults and patients with JME, as well as their clinical interpretation, should be evaluated with psychological condition of a subject taken into account

\section{Conclusion}

Reference corridors for wrist tapping parameters of individual rhythm and individual minute, obtained by us using a patented method, may be used to develop new ways of reference bioadaptation for patients suffering from various types of epilepsy.

\section{Conflict of interest}

Authors have no conflict of interest to disclose.

\section{Ethical approva}

All procedures performed in studies involving human participants were in accordance with the ethical standards of the institutional and with the 1964 Helsinki declaration and its later amendments or comparable ethical standards.

\section{References}

1. O'Muircheartaigh J, Vollmar C, Barker GJ, Kumari V, Symms MR, Thompson $\mathrm{P}$, et al. Abnormal thalamocortical structural and functional connectivity in juvenile myoclonic epilepsy. Brain 2012; 135(Pt 12): 3635-44. https://doi.org/10.1093/brain/aws296.

2. O'Muircheartaigh J, Vollmar C, Barker GJ, Kumari V, Symms MR, Thompson $P$, et al. Frontal lobe function and structure in juvenile myoclonic epilepsy: a comprehensive review of neuropsychological and imaging data. Epilepsia 2012; 53(12): 2091-2098. https://doi.org/10.1093/brain/aws296.

3. Krauss GL. Cognitive activation of "hyperexcitable cortex" in JME: can it trigger seizures? Epilepsy Curr 2011; 11(6): 184-185. https://doi.org/10.5698/1535-7511-11.6.184.

4. Moskaleva PV, Shilkina OS, Artyukhov IP, Strotskaya IG, Dmitrenko DV, Shnayder NA. Nonpsychotic psychiatric disorders in juvenile myoclonic epilepsy. International Journal of Biomedicine 2017; 7(2): 85-90. https://doi.org/10.21103/article7(2) ra1.

5. Bykov YN. Cerebral integrated mechanisms (Message 2). Siberian Medical Journal (Irkutsk) 2001; 25(2): 4-9. Russian. https://elibrary.ru/item.asp?id=17963606.

6. Pogelt B, Roth N, Poget A. Automated rhythmic movements and their control under different experimental conditions. Biomed Biochim Acta 1984; 43(4): 485-491. https://www.ncbi.nlm.nih.gov/pubmed/6487279.

7. Rudnev VA. Functional diagnostics and restoration of voluntary movements in the pathology of the central nervous system. Krasnoyarsk, Russia: Publishing house of Krasnoyarsk University, 1982; 160 p. Russian.

8. Narodova EA, Prokopenko SV, Narodova VV, Narodov AA Rehabilitation of the patients with complex motor aphasia during the ischemic insult. Journal of New Medical Technologies 2012; (1): 40. Russian. https://elibrary.ru/item.asp?id=18296374.

9. Narodova EA, Narodova VV, Izotova OM. Study of internal speech in patients with motor aphasia in the acute phase of the brain stroke by records of tongue micro articulations. Siberian Medical Review 2011; (2): 26-30. https://elibrary.ru/item.asp?id=16376905.

10. Bykov YN. Rehabilitation of stroke patients based functional analyses of sensorimotor processes and referent biological adaptation. Siberian Medical Journal (Irkutsk) 2003; 41(6): 97. Russian. https://elibrary.ru/item.asp?id=17567403.

11. Pokhabov DV, Nesterova YuV, Abramov VG. The method of speech rehabilitation in Parkinson"s disease. The Neurological Journal 2014; 19(5): 29-31. https://elibrary.ru/item.asp?id=22024293.

12. Ukhtomskiy AA. Dominant. Articles of different years. 1887-1939. SPb, Russia: Peter, 2002; 448 p. Russian.

13. Katenis GS, Chibisov SM, Agarval RK. The actual terms of modern chronobiology. Health \& Education Millemmium 2015; 17(1): 4-11. Russian. https://elibrary.ru/item.asp?id=22824552.

14. Svishcheva IA, Olempieva HV, Hodarev NV. Individual minute as a screening method in the evaluation of rehabilitation for people of dangerous professions. Health \& Education Millemmium 2012; 14(1): 44-46. Russian. https://elibrary.ru/item.asp?id=19027580.

15. Gromova VV, Aptukov MI, Tyabut AA. Adopting a procedure personality test minute for express diagnostics psychosomatic condition of children of primary school age. Zdorov'e - Osnova Chelovecheskogo Potentsiala: Problemy i Puti Ikh Resheniya 2014; 9(1): 238-239. Russian. https://elibrary.ru/item.asp?id=25687851.

16. Chiligina YuA. Exam stress effect on subjective evaluation of time among the first-course students. Uchenye Zapiski Universiteta imeni 
P.F. Lesgafta 2015; 4(122): 257-262. Russian. https://elibrary.ru/item.asp?id=23383863.

17. Snaith RP, Zigmond AS. The hospital anxiety and depression scale. $\mathrm{Br}$ Med J (Clin Res Ed) 1986; 292(6516): 344. https://www.ncbi.nlm.nih.gov/pubmed/3080166.

18. Narodova EA, Rudnev VA, Shnayder NA, Narodova VV, Erakhtin EE, Dmitrenko DV, et al. Parameters of the wrist tapping using a modification of the original method (method of exogenous rhythmic stimulation influence on an individual human rhythm). International Journal of Biomedicine 2018; 8(2): 155-158. https://doi.org/10.21103/article8(2) oa10.

19. Narodova EA, Shnayder NA, Narodova VV, Dmitrenko DV, Artyukhov IP. The role of non-drug treatment methods in the management of epilepsy. International Journal of Biomedicine 2018; 8(1): 9-14. https://doi.org/10.21103/article8(1) br.

Authors:

Ekaterina A. Narodova - MD, PhD, Assistant, Department of Nervous Diseases with Course of Medical Rehabilitation, Institute of Postgraduate Education, Krasnoyarsk State Medical University n.a. Prof. V.F. VoinoYasenetsky, Krasnoyarsk, Russia. http://orcid.org/0000-0002-6184-9206.

Natalia A. Shnayder - MD, DSc, Professor, Leading Researcher, Department of Personalized Psychiatry and Neurology, St.Petersburg V.M. Bekhterev Psychoneurological Research Institute, Saint Petersburg, Russia. http://orcid.org/0000-0002-2840-837X.

Valeria V. Narodova - MD, DSc, Professor, Department of Nervous Diseases with Course of Medical Rehabilitation, Institute of Postgraduate Education, Krasnoyarsk State Medical University n.a. Prof. V.F. VoinoYasenetsky, Krasnoyarsk, Russia.

Evgeny E. Erahtin - MD, Neurosurgeon, Krasnoyarsk Interdistrict Clinical Emergency Hospital n.a. N.S. Karpovich, Krasnoyarsk, Russia.

Olga S. Shilkina - MD, PhD student, Department of Medical Genetics and Clinical Neurophysiology, Institute of Postgraduate Education, Krasnoyarsk State Medical University n.a. Prof. V.F. Voino-Yasenetsky, Krasnoyarsk, Russia.

Polina V. Moskaleva - Student, Krasnoyarsk State Medical University n.a. Prof. V.F. Voino-Yasenetsky, Krasnoyarsk, Russia. 